\title{
Use of evidence in hypertension guidelines: should we measure in both arms?
}

\author{
Emily Parker and Paul Glasziou
}

\begin{abstract}
For at least 25 years, hypertension guidelines have suggested measuring blood pressure in both arms, but GPs' acceptance of this is low. Current and past versions of major guidelines were identified to review and assess the degree to which they provided justification, evidence, and a description of dual-arm measurement techniques. It is suggested that if guidelines better justified recommendations and cited primary literature to support claims, a greater percentage of practitioners might accept and adhere to such guidance.

Keywords

blood pressure; guidelines; hypertension.
\end{abstract}

\section{INTRODUCTION}

Hypertension affects approximately $20 \%$ of adults worldwide and is a major, but modifiable, contributory factor in cardiovascular disease such as coronary heart disease and stroke. ${ }^{1}$ Part of the assessment of raised blood pressure should include measurement in both arms, as around $6 \%$ of the adult population has at least a $10 \mathrm{mmHg}$ difference between arms. ${ }^{2}$ This proportion increases with cardiovascular risk factors such as age and diabetes. $^{3}$

An anatomical explanation for this variability has been proposed but there is now evidence to suggest that inter-arm differences are caused by peripheral vascular disease suggesting a pathological, as opposed to physiological, cause. Peripheral vascular disease is a strong predictor of cardiovascular disease, which suggests that interarm differences may also have a prognostic value in predicting cardiovascular events. ${ }^{3}$ As such, it is very important to measure blood pressure in both arms; failure to do so may lead to:

- a delay in the diagnosis of hypertension;

- inadequate treatment of patients with hypertension; and

- physician confusion by spurious, apparent wide fluctuations during monitoring.

E Parker, BA, MBBS, medical student; P Glasziou, PhD, FRCGP, professor, Department of Primary Health Care, Centre for Evidence-Based Medicine, University of Oxford.

Address for correspondence

Professor Paul Glasziou, Department of Primary Health Care, Centre for Evidence-Based Medicine, University of Oxford, Rosemary Rue Building, Headington, Oxford. E-mail: paul.glasziou@dphpc.ox.ac.uk

Submitted: 26 March 2008; Editor's response: 13 May 2008; final acceptance: 21 July 2008.

@British Journal of General Practice.

This is a full-length article of an abridged version published in print and originally published online first. Cite this version as: Br J Gen Pract 2009 DOI: 10.3399/bjgp09X395012 (abridged text, in print: Br J Gen Pract 2009; 59: 206-208).
For many years, guidelines have suggested measuring blood pressure in both arms but have rarely given justification for doing so or described the methods of how to do this. Using a model developed by Pathman et $a l^{4}$ - the awareness-toadherence model - in order for clinicians to change their practice they must first become aware of a guideline, agree with it in principle, decide it is appropriate and feasible, and then adhere to it. Most GPs are aware of the recommendation to initially measure blood pressure in both arms, but only $30 \%$ agree with it and few actually adhere to it. ${ }^{5}$ It is probable that if guidelines cited evidence as to why measuring blood pressure in both arms is important and how to go about it, adherence to them would be greater. 
Therefore, it was, decided to identify current and historical versions of major hypertension guidelines in the UK, Europe, Canada, US, Australia, New Zealand, Japan, and South Africa to review their inclusion of the issue of measuring in both arms. The researchers also wished to assess the degree to which the guidelines provided a justification, evidence, and a description of measurement techniques.

\section{METHOD}

To identify guidelines, MEDLINE was searched using the terms hypertension and guideline* in the title; the researchers then tracked back for earlier versions of each guideline. The section on bloodpressure measurement from each of these guidelines was then identified, and it was assessed whether the guideline suggested measurement of blood pressure in both arms and, if so, provided a justification, referred to evidence to support this, and described a method to measure blood pressure in both arms and whether the method is appropriate.

\section{RESULTS}

In total, 15 guidelines were identified, with several versions for most of these. The oldest found were the 1977 Joint National Committee (JNC) guidelines from the US, which is now in its seventh version. Guidelines were noted for other countries such as Spain and Demark, but were not available in English and so were considered beyond the scope of the present analysis.

Example text on dual-arm measurement extracted from some guidelines are shown in Box 1 (for all quotes see Appendix 1). In total, 13 out of 15 guidelines mentioned the need to measure in both arms; however, one South African guideline surprisingly stated 'all measurements should preferably be taken using the same arm'. ${ }^{6}$ Further, only seven guidelines gave some justification, with only one quantifying the prevalence of substantial arm differences and only one providing a reference to the evidence. No guideline provided a description of appropriate techniques for reliably measuring blood pressure in both arms. Full results are presented in Appendix 1. Table 1 lists the guidelines included with full details in Appendix 2.

\section{DISCUSSION}

Most current guidelines advise that blood pressure should be measured in both arms, at least on the initial visit but, for the most part, do not justify why or provide information on the criteria or methods for deciding there is an important difference. Of those that did justify dual-arm measurement, only one

\section{How this fits in}

Most guidelines on hypertension state that blood pressure should initially be measured in both arms, but few practitioners actually do this. This study found that published guidelines rarely provided either a justification for dual arm measurement or a description of the appropriate technique. Guideline writers should recognise that the information needs of their target users may include the 'why' and 'how' as well as the 'what'.

referenced primary literature to support the claim, and none of the guidelines described a method of taking blood pressure in both arms.

There are some limitations of this review. All the

\section{Box 1. Example statements from selected guidelines.}

American Heart Association 1980: 'On the initial examination, one should record the pressure in both arms."7

- Joint National Committee-3-7: 'The physical examination should include: an appropriate measurement of BP, with verification in the contralateral arm.'8

- British Hypertension Society-4 (2004): 'BP should initially be measured in both arms as patients may have large differences between arms.'

- European Society of Hypertension and European Society of Cardiology practice guidelines 2007: 'Measure BP in both arms at first visit to detect possible differences due to peripheral vascular disease. ${ }^{10}$

- Medicines and Healthcare Products Regulatory Agency (2006): 'BP should initially be measured in both arms ... A difference in BP between the arms can be expected in $20 \%$ of patients. ${ }^{11}$

$B P=$ blood pressure.

Table 1. Hypertension guidelines' reference to measuring initial blood pressure in both arms. ${ }^{a}$

\begin{tabular}{|c|c|c|c|}
\hline & 1980-1989 & 1990-1999 & 2000-2008 \\
\hline $\begin{array}{l}\text { Statement made about } \\
\text { measuring blood pressure } \\
\text { in both arms }\end{array}$ & $\begin{array}{l}\text { JNC-3, JNC-4, } \\
\text { AHA, WHO/ISH }\end{array}$ & $\begin{array}{r}\text { BHS-2, BHS-3, } \\
\text { JNC-5, JNC-6, } \\
\text { WHO/ISH } \\
\text { JS } \\
\text { E } \\
\text { Hear }\end{array}$ & $\begin{array}{l}\text { BHS-4, NICE, } \\
\text { MHRA, CKS } \\
\text { library, JNC-7, } \\
\text { anadian Hypertension } \\
\text { ducation programme, } \\
\text { H, EJCPR, ESH, ESH/ } \\
\text { SC practice guideline, } \\
\text { t Foundation of Australia }\end{array}$ \\
\hline Justified reason & Nil & Nil & $\begin{array}{l}\text { MHRA, ESH, } \\
\text { ESH-ESC guideline, } \\
\text { IS- } 4,{ }^{b} \text { CKS guidelines, } \\
\text { Heart Foundation of } \\
\quad \text { Australia }\end{array}$ \\
\hline Reference(s) given & Nil & Nil & ESH \\
\hline Technique stated & Nil & Nil & Nil \\
\hline
\end{tabular}

aSee Appendices for detailed table and references. ${ }^{\circ}$ Partial justification. AHA = American Heart Association; BHS = British Hypertension Society; CKS = Clinical Knowledge

Summaries; EJCPR = European Journal of Cardiovascular Prevention and Rehabilitation; $E S C=$ European Society of Cardiology; ESH = European Society of Hypertension; JNC = Joint National Committee; MHRA = Medicines and Healthcare Products Regulatory Agency; $\mathrm{JSH}=$ Japanese Society of Hypertension; NICE = National Institute for Health and Clinical Excellence; WHO/ISH = World Health Organization/International Society of Hypertension. 
Working Party of the British Hypertension Society (BHS) guidelines were found, as were all the guidelines from the Joint National Committee; however, other guidelines may have been missed. In addition, while references cited in each guideline were studied, it is possible that references discussing blood pressure in both arms, justification, and methods could have been missed. Further the BHS referred to extra material (on CD), which may have contained this information.

A recent UK survey showed that most (77\%) GPs were aware of the guideline statement to measure blood pressure in both arms, but that only $30 \%$ accepted this was worthwhile and less than $13 \%$ adhered to it. ${ }^{5}$ Without provision of justification or methods, it would appear current guidelines are likely to be ignored by the majority of GPs. If guidelines justified why they recommended blood pressure measurement in both arms and cited primary literature to support the claim, it is probable that a greater percentage of practitioners would agree with those guidelines. Further, if a practical and simple way of accurately measuring blood pressure in both arms was suggested, more practitioners might adopt the practice and adhere to the guidelines.

Many of the guidelines state how blood pressure should be taken and emphasise the importance of positioning of the arm, for example, the Medicines and Healthcare Products Regulatory Agency (2006) states:

'Muscle contraction in an unsupported arm can raise diastolic $B P$ [blood pressure] by as much as $10 \%$, while raising the arm above heart level leads to an underestimation by as much as $10 \mathrm{mmHg}$. The arm should be supported in a horizontal position with the cuff at the level of the heart as denoted by the midsternal level.' 11

With this in mind, taking blood pressure in both arms becomes problematic as, in most consultation rooms, the furniture does not allow both arms to be supported easily. None of the guidelines provide advice on the practicality of measuring blood pressure accurately in both arms in a 10-minute consultation.
GPs appear to be appropriately wary of recommendations unless a justification, together with evidence, is provided. Guideline developers should consider whether users might require additional information to accept and carry out recommendations, and what information this should be.

\section{Competing interests}

The authors have stated that there are none

\section{Acknowledgements}

We would like to thank Nia Roberts for help with finding guidelines.

\section{Discuss this article}

Contribute and read comments about this article on the Discussion Forum: http://www.rcgp.org.uk/bjgp-discuss

\section{REFERENCES}

1. Kearney PM, Whelton M, Reynolds K, et al. Global burden of hypertension: analysis of worldwide data. Lancet 2005; 365(9455): 217-223.

2. Clark CE, Campbell JL, Evans PH, Millward A. Prevalence and clinical implications of the inter-arm blood pressure difference: a systematic review. J Hum Hypertens 2006; 20(12): 923-931.

3. Kimura A, Hashimoto J, Watabe D, et al. Patient characteristics and factors associated with inter-arm difference of blood pressure measurements in a general population in Ohasama, Japan. $J$ Hypertens 2004; 22(12): 2277-2283.

4. Pathman DE, Konrad TR, Freed GL, et al. The awareness-toadherence model of the steps to clinical guideline compliance. The case of pediatric vaccine recommendations. Med Care 1996; 34(9): 873-889.

5. Heneghan C, Perera R, Mant D, Glasziou P. Hypertension guideline recommendations in general practice: awareness, agreement, adoption, and adherence. Br J Gen Pract 2007; 57(545): 948-952.

6. Southern African Hypertension Society Executive Committee 2000. Hypertension clinical guideline 2000. S Afr Med J 2001; 91 (2 Pt 2): 163-172.

7. Kirkendall WM, Feinleib M, Freis ED, Mark AL. Recommendations for human blood pressure determination by sphygmomanometers. Subcommittee of the AHA Postgraduate Education Committee. Circulation 1980; 62(5): 1146A-1155A.

8. Chobanian AV, Bakris GL, Black HR, et al. The seventh report of the Joint National Committee on prevention, detection, evaluation, and treatment of high blood pressure. Hypertension 2003; 42(6): 1206-1252

9 Williams B, Poulter NR, Brown MJ, et al. Guidelines for management of hypertension: report of the fourth working party of the British Hypertension Society, 2004-BHS IV. J Hum Hypertens 2004; 18(3): 139-185.

10. Mancia G, de Backer G, Dominiczak A, et al. 2007 Guidelines for the management of arterial hypertension: the task force for the management of aterial hypertension of the European Society of Hypertension (ESH) and of the European Society of Cardiology (ESC). Eur Heart J 2007; 28(12): 1462-1536.

11. Medicines and Healthcare Products Regulatory. Measuring blood pressure - top 10 tips. MHRA, 2008. http://www.mhra.gov.uk/Publications/Postersandleaflets/CON202 4207 (accessed 24 Oct 2008) 


\section{Appendix 1. Text on dual-arm blood-pressure measurement from major hypertension guidelines.}

\begin{tabular}{|c|c|c|c|c|}
\hline & Quote & ified reasons & Referenced & Method stated \\
\hline \multicolumn{5}{|l|}{ UK guidelines } \\
\hline $\begin{array}{l}\text { BHS recommendations on } \\
\text { BP measurement } 1986\end{array}$ & $\begin{array}{l}\text { BP should be measured in both arms in all patients with high BP } \\
\text { at the initial assessment, and if a reproducible difference } \\
\text { of } 20 \mathrm{mmHg} \text { for systolic pressure and } 10 \mathrm{mmHg} \text { for diastolic } \\
\text { pressure simultaneous measurements should be performed }\end{array}$ & Partial & No & No \\
\hline BHS-1 1989 & - & - & - & - \\
\hline BHS-4 2004 & $\begin{array}{l}\text { BP should initially be measured in both arms as patients may have } \\
\text { large differences between arms }\end{array}$ & Partial & No & No \\
\hline NICE 2006 & Measure blood pressure on both of the patient's arms & No & No & No \\
\hline MHRA 2006 & $\begin{array}{l}\text { BP should initially be measured in both arms ... A difference in } B P \\
\text { between the arms can be expected in about } 20 \% \text { of patients }\end{array}$ & Yes & No & No \\
\hline \multicolumn{5}{|l|}{ US and Canadian guidelines } \\
\hline JNC-1 1977, JNC-2 1980 & - & - & - & - \\
\hline $\begin{array}{l}\text { JNC-3 1984, JNC-4 1988, } \\
\text { JNC-5 1993, JNC-6 1997, } \\
\text { JNC-7 } 2003\end{array}$ & $\begin{array}{l}\text { The physical examination should include: an appropriate } \\
\text { measurement of BP, with verification in the contralateral arm }\end{array}$ & No & No & No \\
\hline AHA 1980 & On the initial examination, one should record the pressure in both arms & No & No & No \\
\hline $\begin{array}{l}\text { Canadian hypertension } \\
\text { education program } 2007 \\
\text { and } 2008\end{array}$ & BP should be taken in both arms on at least one visit. & No & No & No \\
\hline \multicolumn{5}{|c|}{ New Zealand, Australian and Japanese guidelines } \\
\hline $\begin{array}{l}\text { Heart Foundation of } \\
\text { Australia } 2008\end{array}$ & $\begin{array}{l}\text { At the patient's first BP assessment, measure the BP } \\
\text { on both arms, thereafter, use the arm with the higher reading }\end{array}$ & No & No & No \\
\hline $\begin{array}{l}\text { Heart Foundation of } \\
\text { Australia } 2004\end{array}$ & $\begin{array}{l}\text { Measure BP on both arms at the first visit, particularly if there is } \\
\text { evidence of peripheral vascular disease. A variation of up to } 5 \mathrm{mmHg} \\
\text { in BP between arms can be acceptable }\end{array}$ & No & No & No \\
\hline $\begin{array}{l}\text { New Zealand Cardiovascular } \\
\text { Guidelines } 2005\end{array}$ & Not mentioned & - & - & - \\
\hline JSH 2003 & $\begin{array}{l}\text { The BP difference between the arms must be evaluated. If a difference } \\
\text { of BP between the arms is apparent, the BP should usually be } \\
\text { measured with the arm that shows the higher BP }\end{array}$ & No & No & No \\
\hline \multicolumn{5}{|l|}{ South African Guidelines } \\
\hline $\begin{array}{l}\text { Hypertension Guideline } \\
2003,2000\end{array}$ & All measurements should preferably be taken using the same arm & No & No & No \\
\hline Hypertension guideline 1995 & Not mentioned & - & - & - \\
\hline \multicolumn{5}{|l|}{ International guidelines } \\
\hline $\begin{array}{l}\text { WHO/ISH } 1989 \\
\text { WHO/ISH } 1999\end{array}$ & $\begin{array}{l}\text { Measure the blood pressure in both arms on the first visit } \\
\text { if there is evidence of peripheral vascular disease }\end{array}$ & No & No & No \\
\hline $\begin{array}{l}\text { ESH-ESC practice guidelines } \\
\text { 2007, ESH-ESC } 2003\end{array}$ & $\begin{array}{l}\text { Measure BP in both arms at first visit to detect possible differences } \\
\text { due to peripheral vascular disease }\end{array}$ & Yes & No & No \\
\hline ESH 2003 & $\begin{array}{l}\text {... a recent study has shown significant differences in inter-arm differences } \\
\text { for systolic and diastolic blood pressure, leading to the recommendation } \\
\text { that bilateral measurement should be made on first consultation ... }\end{array}$ & Yes & Yes & No \\
\hline EJCPR 2003 & $\begin{array}{l}\text { At the initial visit, BP values from both arms should be obtained to } \\
\text { detect patients in whom atherosclerotic plaques in subclavian or } \\
\text { more central arteries may be responsible for substantial } \\
\text { between-arm discrepancies }\end{array}$ & Yes & No & No \\
\hline
\end{tabular}

Note: Justification has been italicised. AHA = American Heart Association; BHS = British Hypertension Society; BP = blood pressure; CKS = Clinical Knowledge Summaries; EJCPR = European Journal of Cardiovascular Prevention and Rehabilitation; ESC = European Society of Cardiology; ESH = European Society of Hypertension; JNC = Joint National Committee; MHRA = Medicines and Healthcare Products Regulatory Agency; JSH = Japanese Society of Hypertension; NICE: National Institute for Health and Clinical Excellence; WHO/ISH = World Health Organisation/International Society of Hypertension. 


\section{Appendix 2. List of guidelines.}

\section{British guidelines}

BHS-4. Williams B, Poulter NR, Brown MJ, et al. Guidelines for management of hypertension: report of the fourth working party of the British Hypertension Society, 2004-BHS IV. J Hum Hypertens 2004; 18(3): 139-185.

BHS-3. Ramsay L, Williams B, Johnston G, et al. Guidelines for management of hypertension: report of the third working party of the British Hypertension Society. J Hum Hypertens 1999; 13(9): 569-592.

BHS-2. Sever P, Beevers G, Bulpitt C, et al. Management guidelines in essential hypertension: report of the second working party of the British Hypertension Society. BMJ 1993; 306(6883): 983-987.

BHS-1. [Anonymous.] Treating mild hypertension. Report of the British Hypertension Society working party. BMJ 1989; 298(6675): 694-698.

- Petrie JC, O'Brien ET, Littler WA, de Swiet M. Recommendations on blood pressure measurement. Br Med J (Clin Res Ed) 1986; 293(6547): 611-615.

- MHRA. Measuring blood pressure - top 10 tips. http://www.mhra.gov.uk/Publications/Postersandleaflets/CON2024207 (accessed 7 Oct 2008).

- National Institute for Health and Clinical Excellence. Hypertension: management of hypertension in adults in primary care. NICE guidance CG34. London: NICE, 2006. http://www.nice.org.uk/Guidance/CG34 (accessed 24 Oct 2008)

- CKS Library. Hypertension. 2007. http://www.cks.library.nhs.uk/hypertension/view_whole_guidance (accessed 7 Oct 2008).

US and Canadian guidelines

- JNC-7. Chobanian AV, Bakris GL, Black HR, et al. Seventh report of the Joint National Committee on prevention, detection, evaluation, and treatment of High Blood Pressure. Hypertension 2003; 42(6): 1206-1252.

JNC-6. Anonymous. The sixth report of the Joint National Committee on prevention, detection, evaluation, and treatment of high blood pressure. Arch Intern Med 1997; 157(21): 2413-2446.

JNC-5. Anonymous. The fifth report of the Joint National Committee on detection, evaluation, and treatment of high blood pressure. Arch Intern Med 1993; 153(2): 154-183.

- JNC-4. Anonymous. The 1988 report of the Joint National Committee on detection, evaluation, and treatment of high blood pressure. Arch Intern Med 1988; 148(5): 1023-1038.

- JNC-3. Anonymous. The 1984 Report of the Joint National Committee on detection, evaluation, and treatment of high blood pressure. Arch Intern Med 1984; 144(5): 1045-1057.

- JNC-2. Anonymous. The 1980 report of the Joint National Committee on detection, evaluation, and treatment of high blood pressure. Arch Intern Med 1980; 140(10): 1280-1285.

- JNC-1. Anonymous. Report of the Joint National Committee on detection, evaluation, and treatment of high blood pressure. A cooperative study. JAMA 1977; 237(3): 255-261.

- AHA. Kirkendall WM, Feinleib M, Freis ED, Mark AL. Recommendations for human blood pressure determination by sphygmomanometers. Subcommittee of the AHA Postgraduate Education Committee. Circulation 1980; 62(5): 1146A-1155A.

- Canadian Hypertension Education Program. 2008 CHEP recommendations for the management of hypertension. http://hypertension.ca/chep/wp-content/uploads/2008/03/2008-chepspiral-booklet-final_jan28.pdf (accessed 7 Oct 2008).

- Canadian Hypertension Education Programme. Accurate measurement of blood pressure. http://hypertension.ca/chep/recommendations/diagnosis-assessment/accurate-measurement-of-blood-pressure/ (accessed 24 Oct 2008)

Australian, New Zealand and Japanese guidelines

- The National Heart Foundation of Australia. New hypertension guidelines. http://www.heartfoundation.org.au/Professional_Information/Clinical_Practice/Hypertension.htm (accessed 24 Oct 2008).

- The National Heart Foundation of Australia. Hypertension management guide for doctors 2004. http://www.sld.cu/galerias/pdf/servicios/hta/hypertension_management_guide_australia_2004.pdf (accessed 24 Oct 2008).

- New Zealand Guidelines Group. New Zealand cardiovascular guidelines handbook: developed for primary care practitioners. New Zealand Guidelines Group, 2005.

Imai Y, Otsuka K, Kawano Y, et al. Japanese Society of Hypertension (JSH) guidelines for self-monitoring of blood pressure at home. Hypertens Res 2003; 26(10): 771-782. 


\section{Appendix 2 continued. List of guidelines.}

South African guidelines

Milne FJ, Pinkney-Atkinson VJ. Hypertension guideline 2003 update. S Afr Med J 2004; 94: 209-226.

- Southern African Hypertension Society Executive Committee 2000. Hypertension clinical guideline 2000. S Afr Med J 2001; 91(2 Pt 2): 163-172.

- Opie LH, Steyn K. Rationale for the hypertension guidelines for primary care in South Africa. S Afr Med J 1995; 85(12 Pt 2): 1325-1328, 1330-1331, 1334-1335 passim.

International guidelines

Mancia G, de Backer G, Dominiczak A, et al. 2007 Guidelines for the management of arterial hypertension: The task force for the management of aterial hypertension of the European Society of Hypertension (ESH) and of the European Society of Cardiology (ESC). Eur Heart J 2007; 28(12): 1462-1536.

- European Society of Hypertension - European Society of Cardiology Guidelines Committee. European Society of Hypertension European Society of Cardiology guidelines for the management of arterial hypertension. $J$ Hypertens 2003; 21(6): 1011-1053.

- O'Brien E, Asmar R, Beilin L, et al. European Society of Hypertension recommendations for conventional, ambulatory and home blood pressure measurement. $J$ Hypertens 2003; 21(5): 821-848.

- European guidelines on cardiovascular disease prevention in clinical practice Third Joint Task Force of European and other Societies on Cardiovascular Disease Prevention in Clinical Practice (constituted by representatives of eight societies and by invited experts). Eur $J$ Cardiovasc Prev Rehabil 2003; (Suppl 10): S1-S78.

1999 World Health Organisation - International Society of Hypertension guidelines for the management of hypertension. Guidelines Subcommittee. J Hypertens 1999; 17(2): 151-183.

- 1980 guidelines for the management of mild hypertension: memorandum from a WHO/ISH meeting. Bull World Health Organ 1989; 67: 493-498. 